\title{
Evaluation of low doses of Azathioprine in reducing relapse and corticosteroid dependence in patients with Ulcerative Colitis
}

\author{
Maryam Rezaiee $^{1(D)}, \underline{\text { Hasan Salman-Roghani }^{2}}{ }^{(D)}$, Meisam Sargazi $^{3}(\mathbb{D})$ Fatemeh Mahdizadeh $^{1}$ \\ ${ }^{1}$ Cardiovascular disease research center, Department of Internal Diseases, Birjand University of Medical Science, Birjand, Iran. \\ ${ }^{2}$ Corresponding author; Department of Internal Diseases, Yazd University of Medical Science, Yazd, Iran. \\ Tel: +3536232525Ｅmail: salmanroghani@hotmail.com \\ ${ }^{3}$ Medical Students Research 's Center, Zahedan University of Medical Science, Zahedan, Iran
}

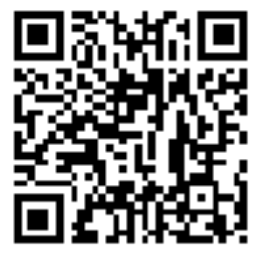

Citation Rezaiee M, Salman-Roghani H, Sargazi M, Mahdizadeh F. [Evaluation of low doses of Azathioprine in reducing relapse and corticosteroid dependence in patients with Ulcerative Colitis]. J Birjand Univ Med Sci. 2019; 26(2): 157-64. [Persian]

DOI http://doi.org/10.32592/JBirjandUnivMedSci.2019.26.2.107

Received: November 27, 2018

Accepted: April 6, 2019

\begin{abstract}
Background and Aim: Ulcerative Colitis is an idiopathic inflammatory bowel disease that is common in adults. Although corticosteroids are the most effective preservative treatment for Ulcerative Colitis. However, due to the dependence of these drugs and their serious complications, the use of an immunosuppressive drug or surgery should be taken seriously. Thus the aim of the study was the evaluation of the efficiency of low doses of azathioprine (AZA) in reducing relapse and corticosteroid-dependence in Ulcerative colitis patients.

Materials and Methods: In this cross-sectional study, 96 patients with ulcerative colitis were followed for one year. Patients who indicated by corticosteroid therapy not able to reduce the dose of corticosteroid, at second relapse was treated with $1-1.5 \mathrm{mg} / \mathrm{kg}$ of (AZA). Demographic characteristics, the severity of disease at the beginning of the study and response to treatment, recurrence of the disease, and drug side effects during the study. Data were analyzed using the Chi-square test in SPSS software.

Results: At the beginning of the study, over $50 \%$ of patients had high symptoms of the disease. In the patients under study, 40 $(41.7 \%)$ patients had corticosteroid dependence, all of them being treated with (AZA).Of the 96 patients during the one-year followup 24 patients had relapses and 72 patients did not have relapses. 97.8\% of corticosteroid patients with (AZA) prescription, Corticosteroid was discontinued and only one patient did not response to AZA and was underwent surgery.
\end{abstract}

Conclusion: Given the prevalence of use of corticosteroids, prescription of low doses of (AZA) can be considered as one of the effective therapies to reduce the rate of relapse of the disease and to avoid frequent use of corticosteroids.

Key Words: Ulcerative Colitis; Corticosteroid; Azathioprine; Relapse of the Disease 


\section{بررسى كار آيى آزاتيويرين با دوزهاى پايين در كاهش عود و وابستكى به

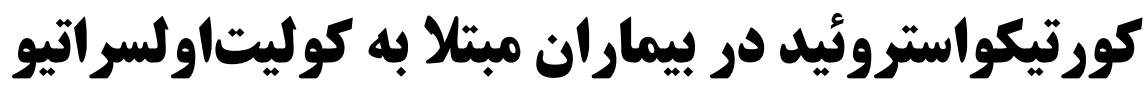

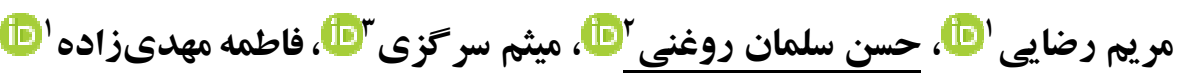

$$
\text { جكيuه }
$$

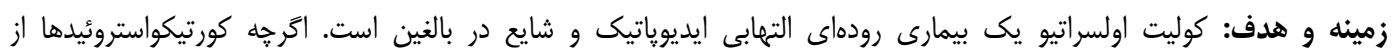

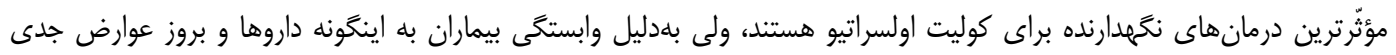

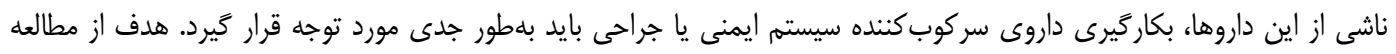

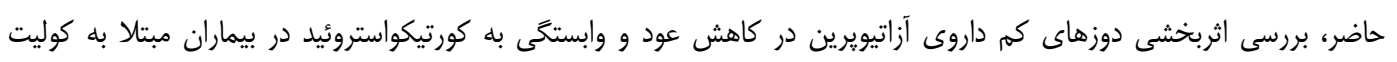

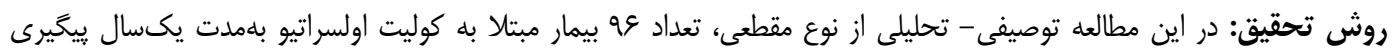

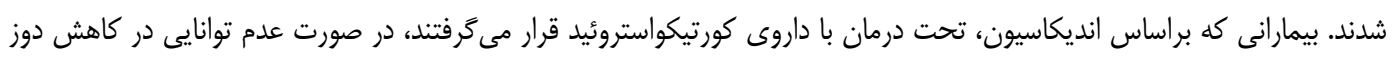

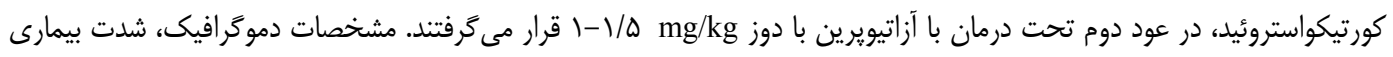

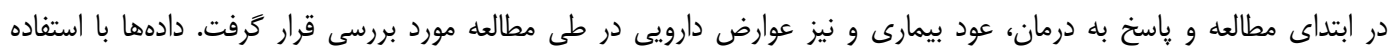

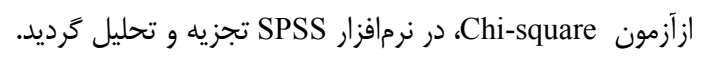

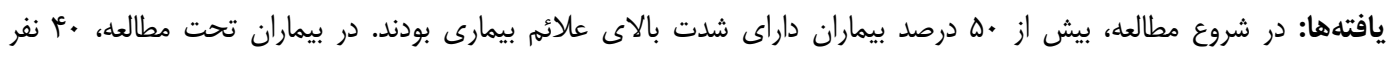

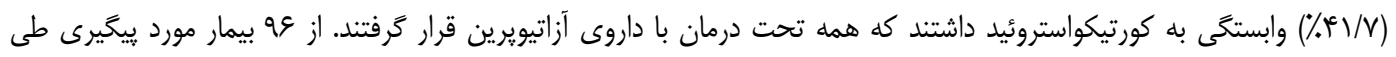

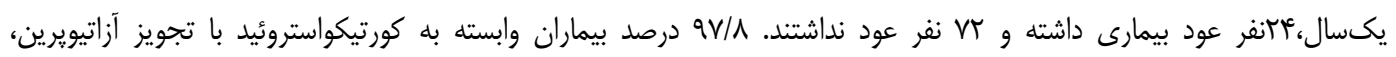

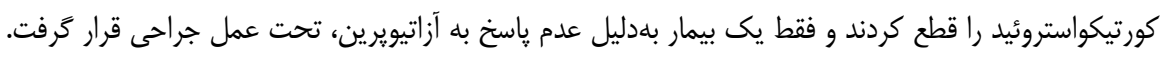

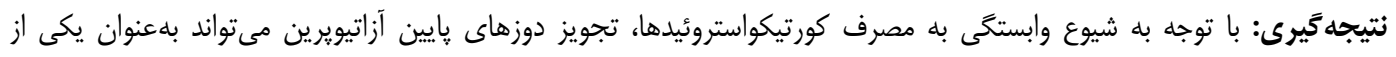

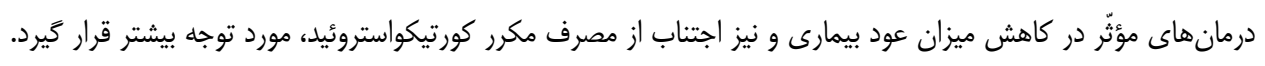
وازههاى كليدى: كوليت اولسراتيو؛ كورتيكواستروئيد؛ آزاتيويرين؛ عود بيمارى

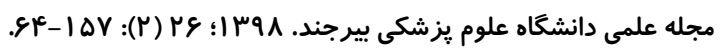

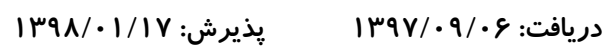

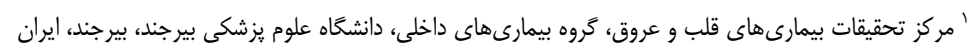

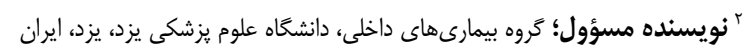

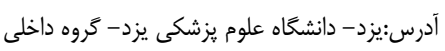
يست الكترونيكى: salmanroghani@hotmail.com

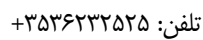
" كميته تحقيقات دانشجويى، دانشخاه علوم يزشكى زاهدان، زاهدان، ايران 
زندكَى اين افراد كه جزء قشر فعال جامعله هستند، نياز به

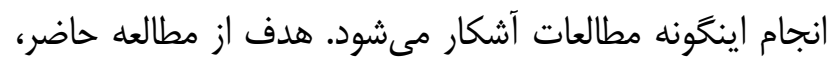

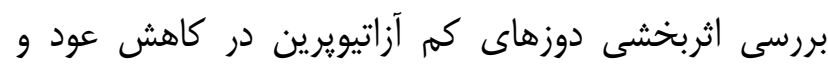

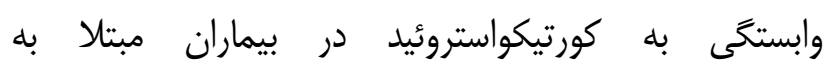
كوليتاولسراتيو بود.

\section{روش تحقيق}

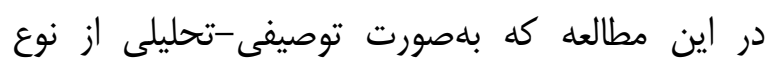
مقطعى انجام شد، از •إ بيمار كوليتاولسراتيو مراجعه كننده

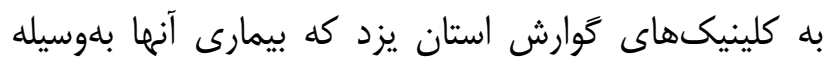

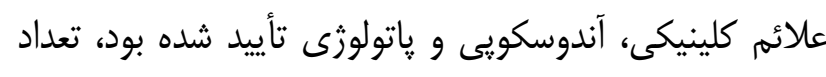

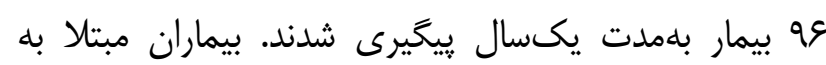

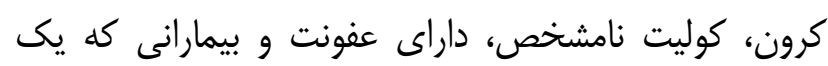

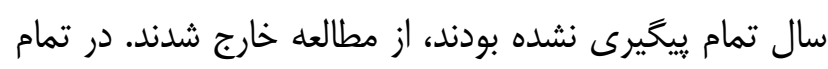

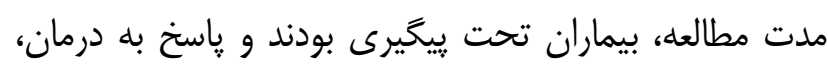

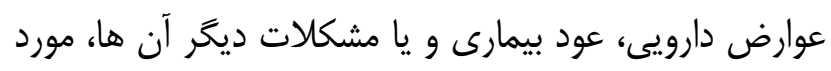

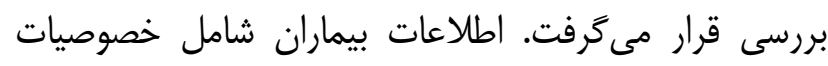

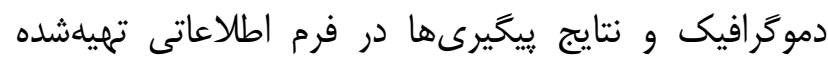

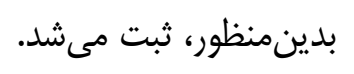

در نهايت در هايان يكسال، وضعيت تمام بيماران و ميزان

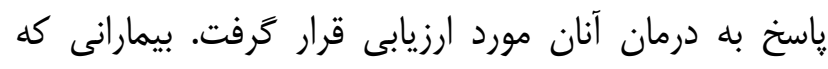

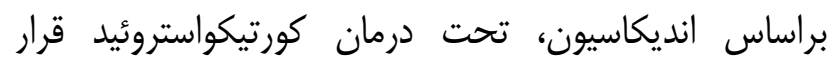

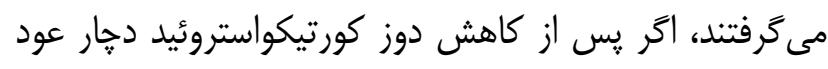

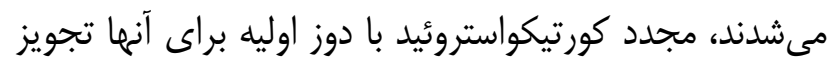

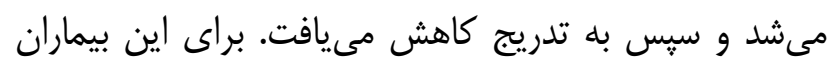

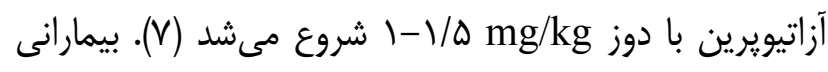
كه تحت درمان با آزاتيويرين بودند، تحت بييخيرى قرار كرانته

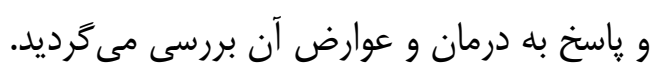

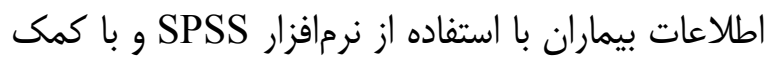

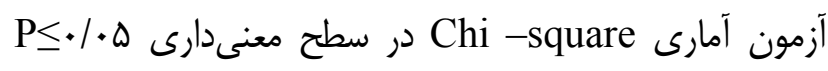

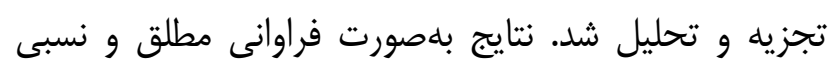
كزارش كرديد. لازم به ذكر است مطالعه حاضر داراى كد ندان
مقله

كوليت اولسراتيو يك بيمارى رودهاى التهابى ايديوياتيك

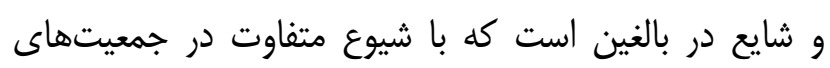

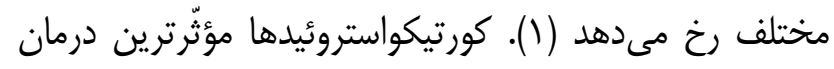

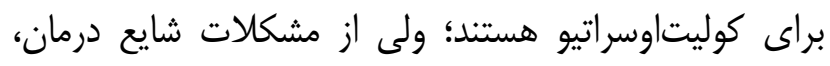

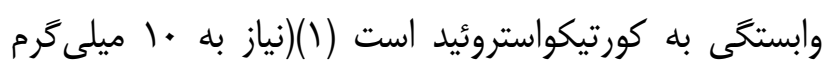

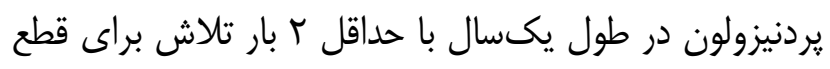

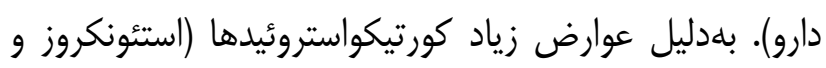

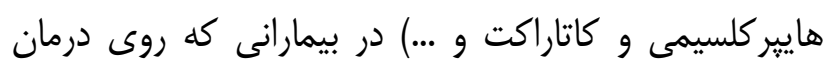

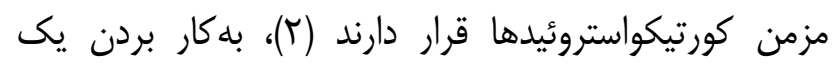

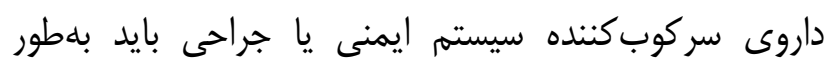

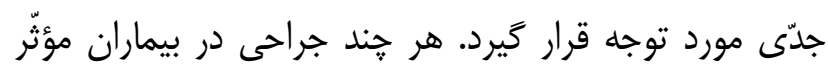

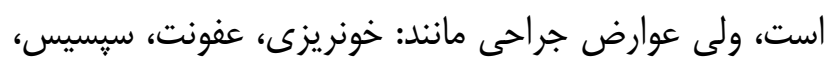

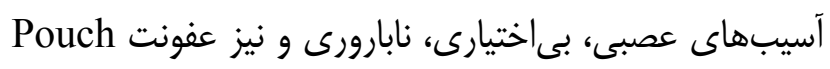

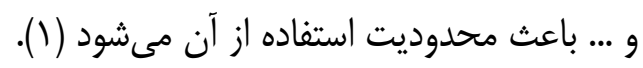

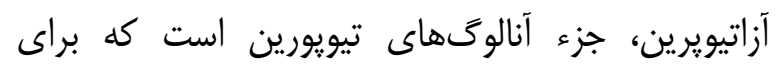
درمان بيمارى هاى التهابى روده استفاده مىشود (1). بر اساس تراس

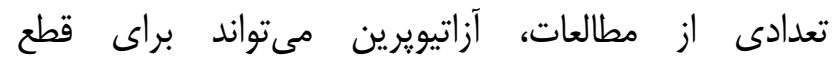

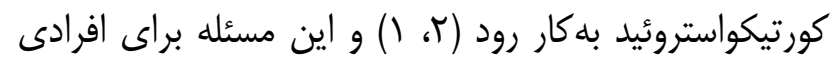

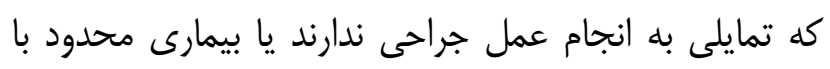

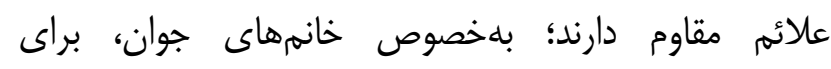

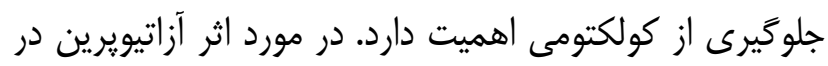

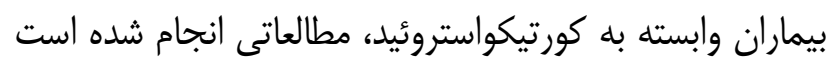

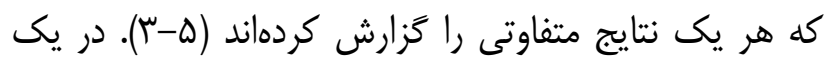

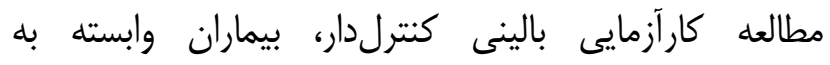

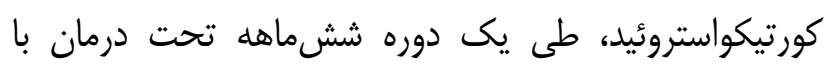

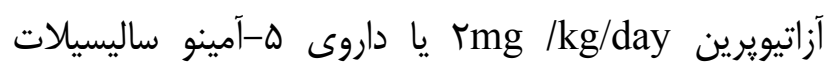

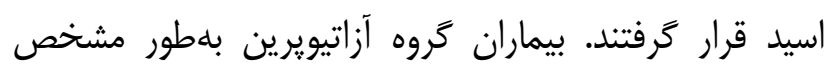

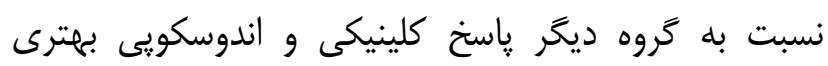

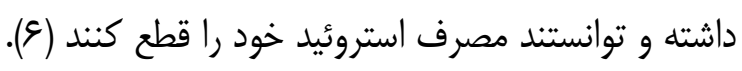

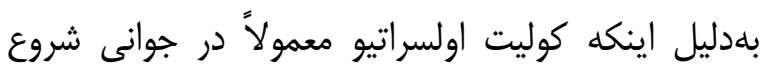

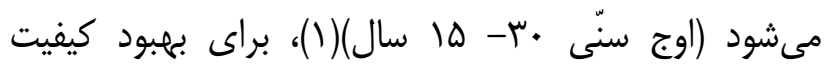




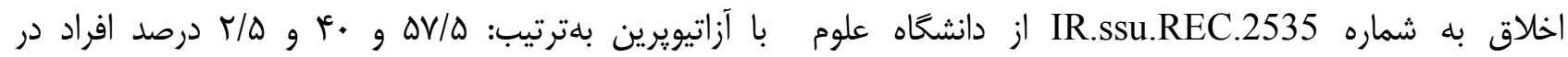
طبقهاى شديد، متوسط و خفيف قرار داشتند. بين شدت يزشكى شهيد صدوقى يزد مىباشد.

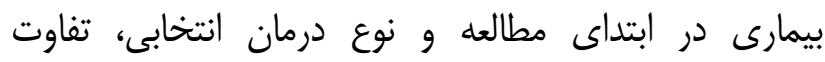

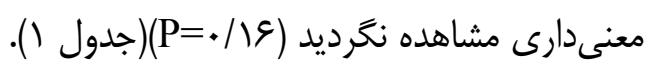

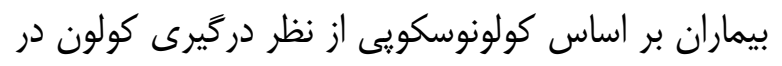

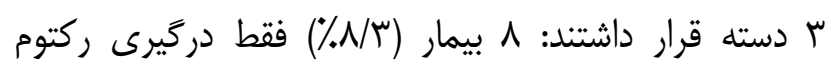

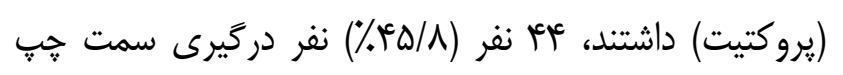

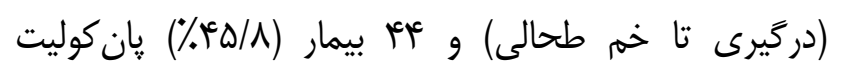

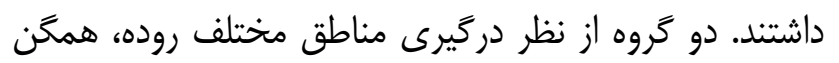

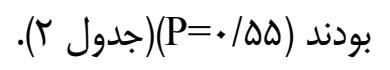

يافته ها

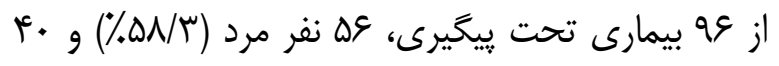

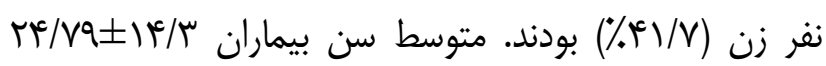

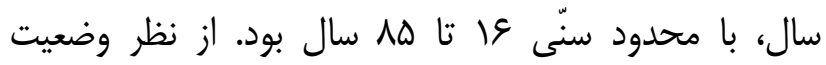

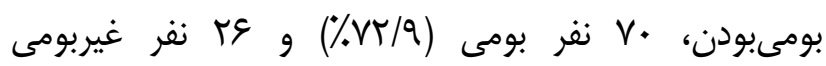

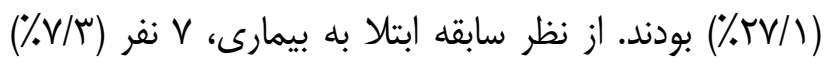
در بيماران وابسته به كورتيكواستروئيد كه همكى تحت سابقه فاميلى مثبت كوليتاولسراتيو داشتند.

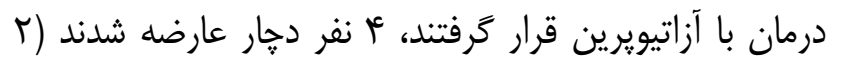

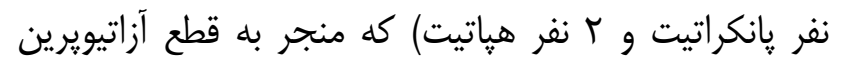

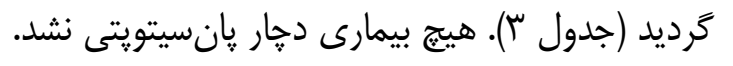

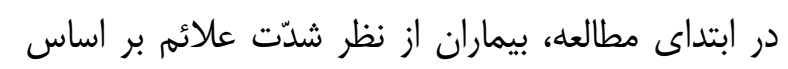

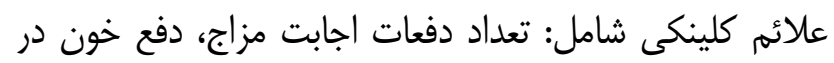

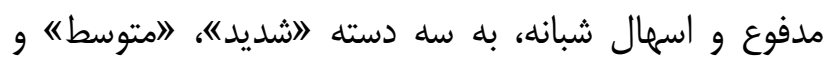

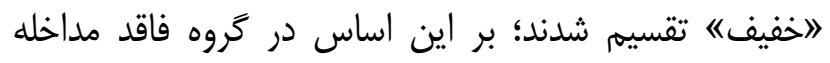
بلترتيب:

جدول ا - ارتباط بين شدّت بيمارى و دريافت تجويز آزاتيويرين در افراد تحت مطالعه

\begin{tabular}{|c|c|c|c|c|c|c|}
\hline \multicolumn{2}{|c|}{ جمع } & \multicolumn{2}{|c|}{ عدم دريافت دارو } & \multicolumn{2}{|c|}{ دريافت دارو } & \multirow{2}{*}{ شدّت بيمارى } \\
\hline درصد & ت تعداد & درصد & تعداد & درصد & تعداد & \\
\hline$\Delta \cdot$ & « & $p e / s$ & $r \Delta$ & $\Delta V / \Delta$ & 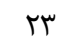 & 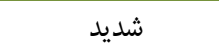 \\
\hline $41 / V$ & c. & ET/Q & Tr & f. & 19 & متوسط \\
\hline$\Lambda / r$ & $\wedge$ & $1 Y / \Delta$ & $\checkmark$ & $r / \Delta$ & 1 & خفيف \\
\hline $1 \cdots$ & १६ & $1+$. & $\Delta S$ & $1 \cdots$ & f. & 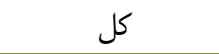 \\
\hline \multicolumn{6}{|c|}{$\mathrm{X} 2=r / q) ، \mathrm{df}=r, \mathrm{P}=. / 1 \varphi$} & نتيجه آزمون كاىدو \\
\hline
\end{tabular}

جدول r- ارتباط بين ميزان دركيرى كولون و دريافت تجويز آزاتيويرين در افراد تحت مطالعه

\begin{tabular}{|c|c|c|c|c|c|c|}
\hline \multicolumn{2}{|c|}{ جمع } & \multicolumn{2}{|c|}{ عدم دريافت دارو } & \multicolumn{2}{|c|}{ دريافت دارو } & \multirow{2}{*}{ مكان دركيرى كولون } \\
\hline درصد & تعداد & درصد & تعداد & درصد & تعداد & \\
\hline$\Lambda / \mu$ & $\wedge$ & $1 \cdot / V$ & 9 & $\Delta$ & $r$ & ركتوم \\
\hline$f \Delta / \Lambda$ & pe & $\mid \notin / K^{c}$ & ז & id & $M$ & سمت جֶٍ \\
\hline eQ/A & pe & $F T / 9$ & te & $\omega \cdot$ & $r \cdot$ & تمام كولون \\
\hline $1 \cdots$ & १९ & $1 \ldots$ & $\Delta F$ & $1 .$. & f. & كل \\
\hline \multicolumn{6}{|c|}{$\mathrm{X} 2=1 / \backslash \wedge, \mathrm{df}=r, \mathrm{P}=\cdot / \Delta \omega$} & نتيجه آزمون كاىدو \\
\hline
\end{tabular}


جدول بـ توزيع فراوانى مطلق و نسبى بروز عوارض دارويى در افراد تحت درمان با آزاتيويرين

\begin{tabular}{|c|c|c|}
\hline درصد & تعداد & عوارض مصرف آزاتيويرين \\
\hline$V / 9$ & $r$ & دارد \\
\hline $9 \% / 1$ & rV & 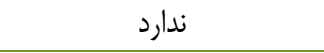 \\
\hline $1 .$. & r. & 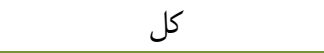 \\
\hline
\end{tabular}

جدول F- مقايسه توزيع فراوانى مطلق و نسبى موارد عود بيمارى در مدت يكسال در تروههاى مورد مطالعه

\begin{tabular}{|c|c|c|c|c|c|c|}
\hline \multicolumn{2}{|c|}{ جمع } & \multicolumn{2}{|c|}{ عدم دريافت دارو } & \multicolumn{2}{|c|}{ دريافت دارو } & \multirow{2}{*}{ عود بيمارى } \\
\hline درصد & تعداد & درصد & تعداد & درصد & تعداد & \\
\hline ro & re & זr & $M$ & 10 & $9 *$ & دارد \\
\hline VQ & vr & $9 \Lambda$ & r & $1 \Delta$ & re & 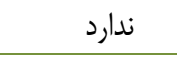 \\
\hline $1 .$. & 99 & $1 .$. & $\Delta S$ & $1 .$. & r. & كل \\
\hline \multicolumn{6}{|c|}{$\mathrm{X} 2=r / 9 \Delta, \mathrm{df}=1, \mathrm{P}=. / 4 \Delta$} & لمه آزمون كايدو \\
\hline
\end{tabular}

"*: در كروه تحت درمان با آزاتيويرين، در مجموع عا نوبت عود بيمارى مشاهده كرديد .

داشتند (9) كه در مطالعه حاضر اين ميزان V/أدرصد بلهدست

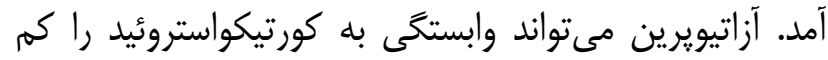

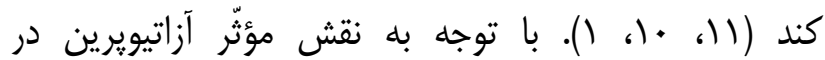

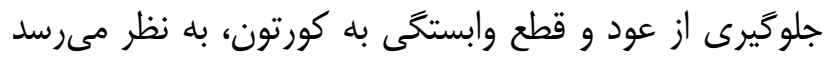

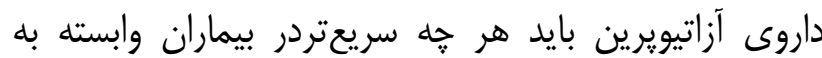

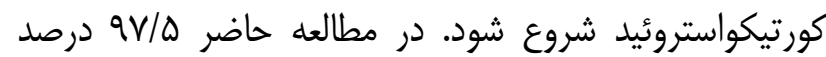

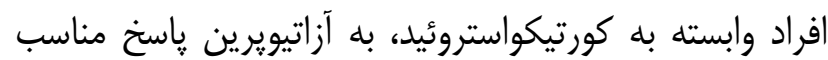

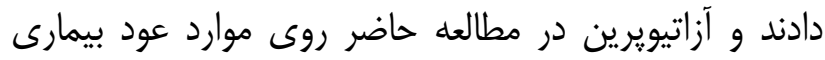

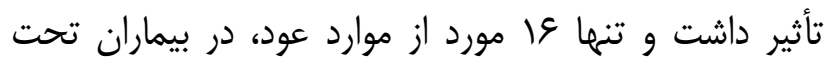

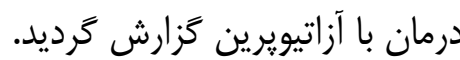

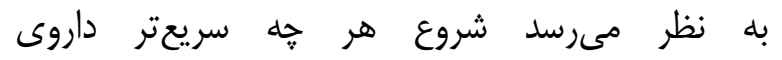

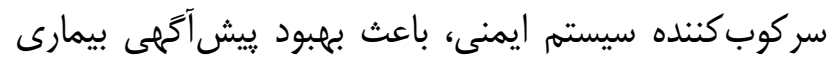

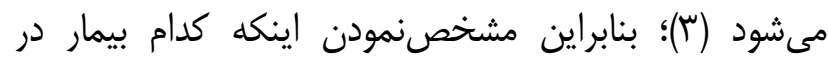

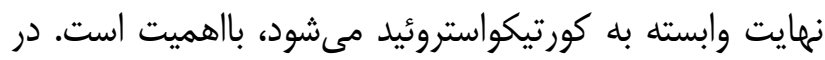
مطالعه حاضر هيج ارتباطى بين سن و جنس، وسعت گرَفتارى

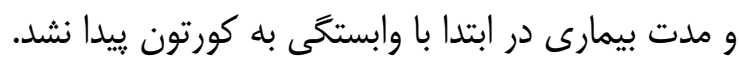

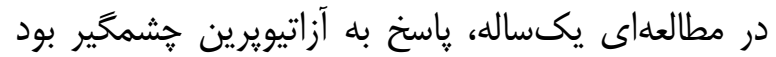

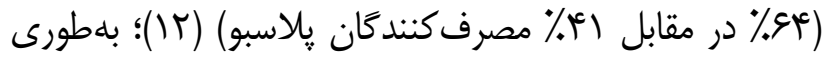

از عq بيمار تحت مطالعه در مجموع تعداد ع نفر عود

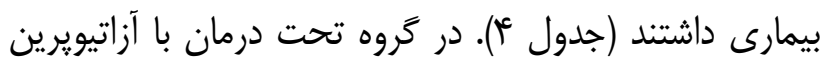

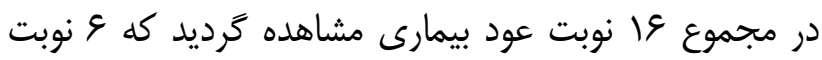

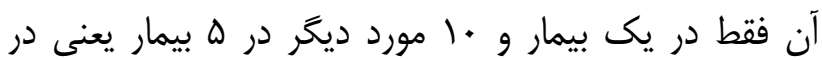

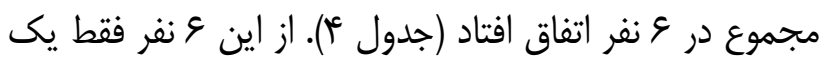
بيمار در نهايت تحت عمل جراحى قرار گرفت.

در اين مطالعه يك ساله، از بين عو بيمار تحت مطالعه

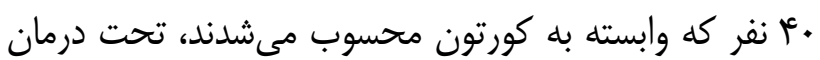

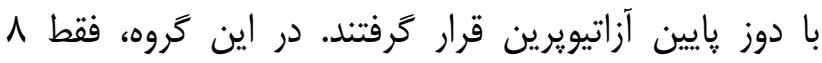

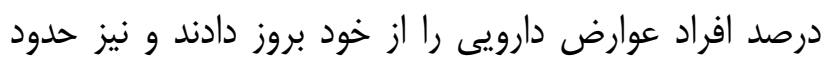
ها درصد عود بيمارى داشتند كه قابل تعمل مىباشد. بر طبق برخى از مطالعات انجامشده، اخر خه هيه بيماران

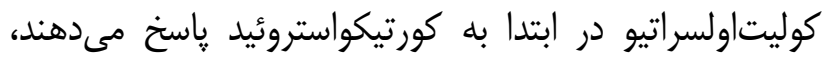

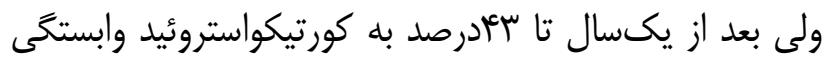

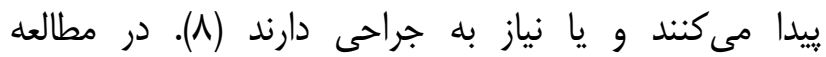
Faubion 
بيانشده است. با توجه به شيوع كوليت اولسراتيو در دها دوم

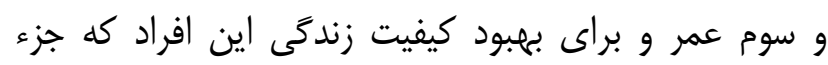

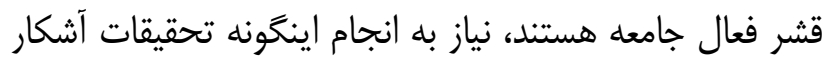
مى گردد.

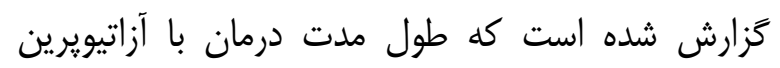
تأثيرى بر روى ميزان عود بيمارى بعد از توقف درمان ندارد؛

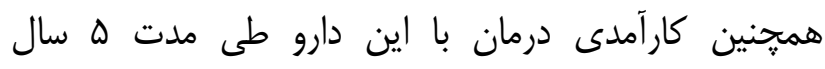

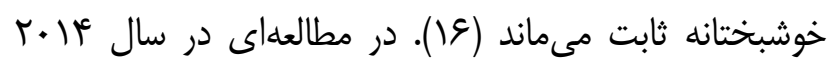

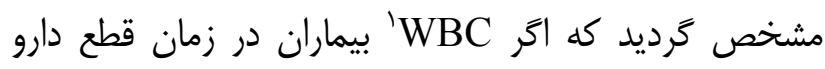

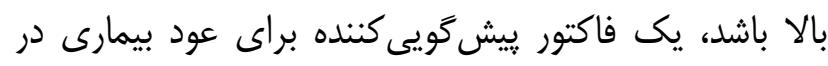

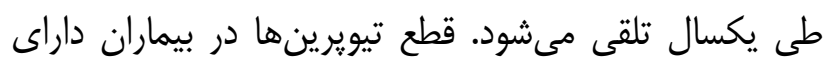

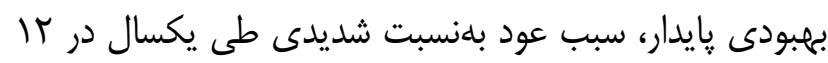

درصد بيماران كوليت اولسراتيو گرديد (IV).

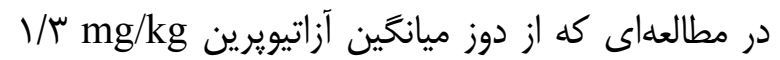

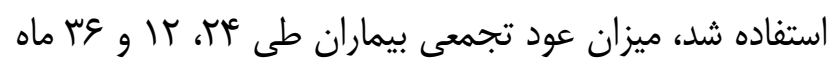

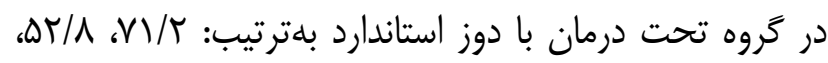

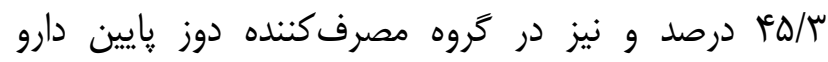

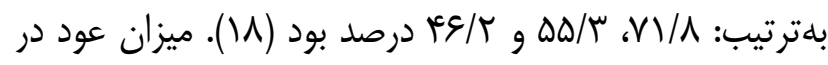

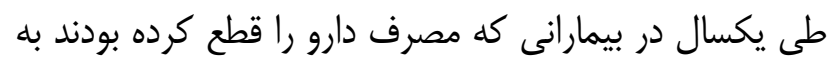

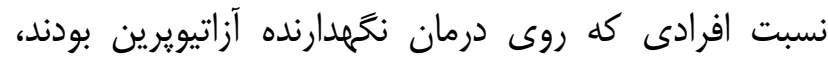

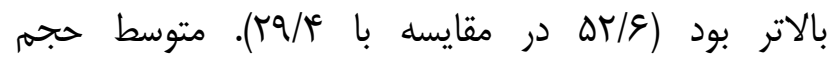

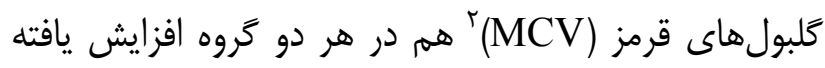

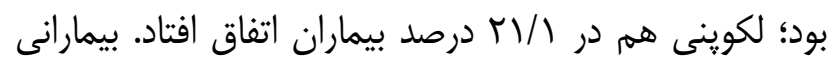

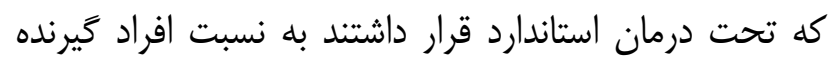
دوز كم، داراى خطر بالاترى براى ابتلا به لكوينى بودند (1) (I).

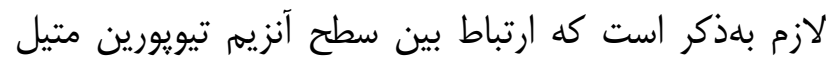

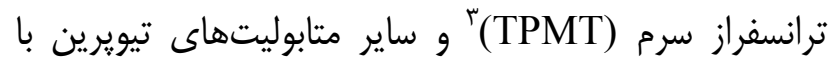

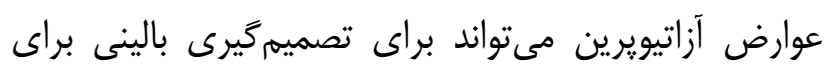

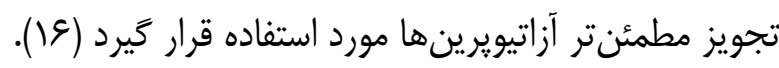
نتايج مطالعه حاضر و ساير مطالعات مشابه در اين زمينه

\footnotetext{
${ }^{1}$ White Blood Cell

${ }^{2}$ Mean Cell Volume

${ }^{3}$ Thiopurine Methyl transferase Enzyme
}

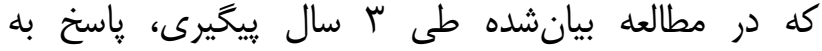

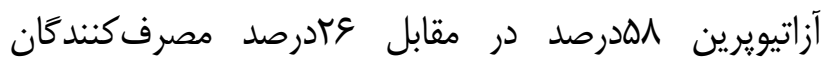

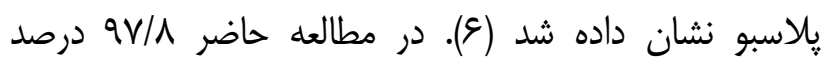

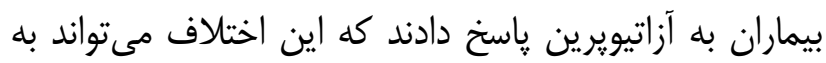

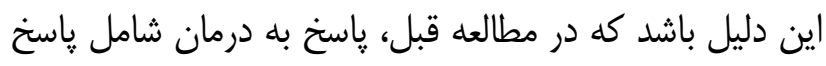

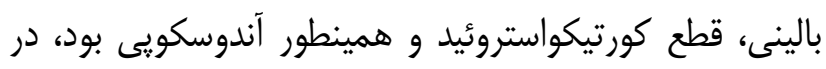

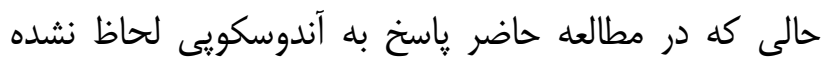

كزارشها حاكى از آن است كه با وجود اثرات خوب

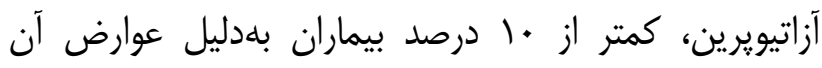

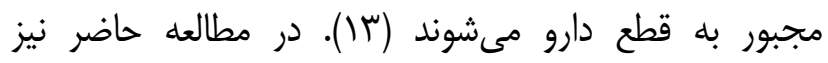

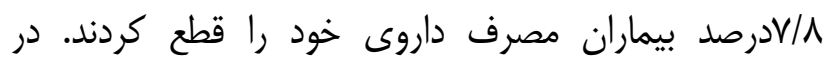

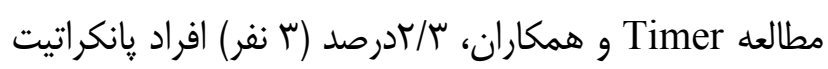

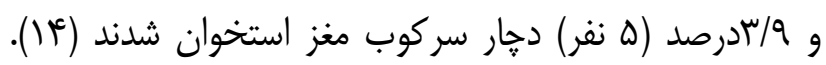

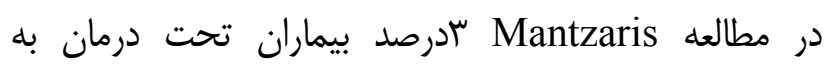

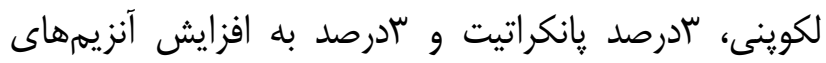

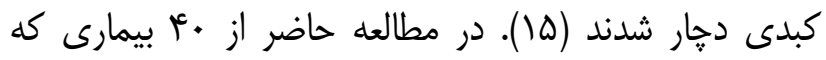

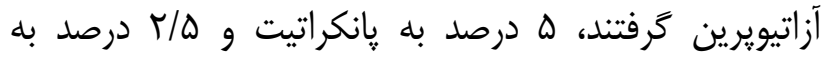
هياتيت دجار شده و مجبور به قطع دارو شدند. در مطالعه حاضر در بين بيمارانى كه بلهمدت يكست دهال

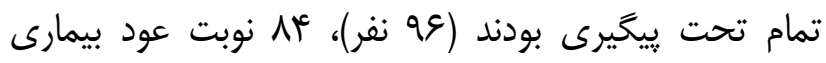

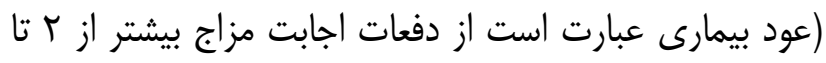

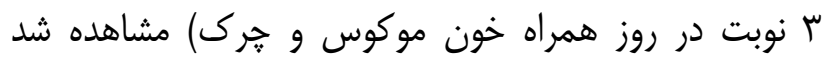

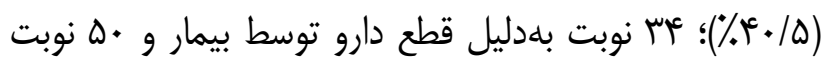

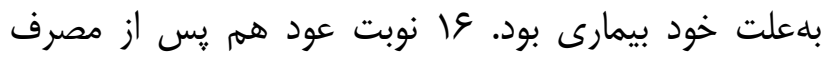

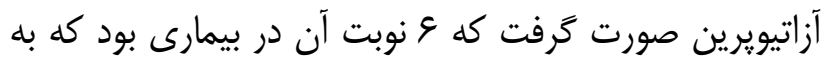
درمان طبى جوابى نداد و تحت كولكتومى قرار گرفت. تعداد زياد موارد عود ناشى از قطع دارو مى جوانى نداند بهدليل يذيرش

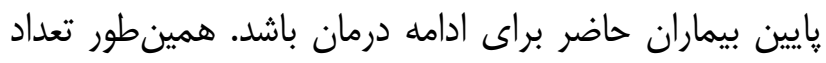

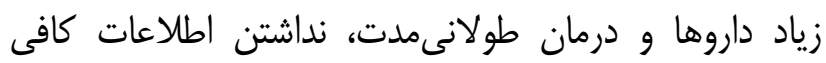

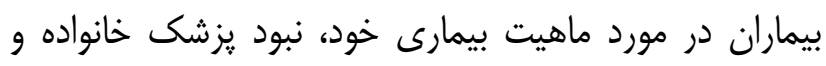

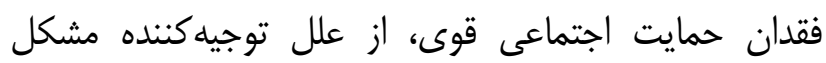


حاكى از آن است كه وابستخى به كورتيكواستروئيد يكى از نخرفته بود كه بتوان از روشهاى اندازهخيرى مكرر استفاده

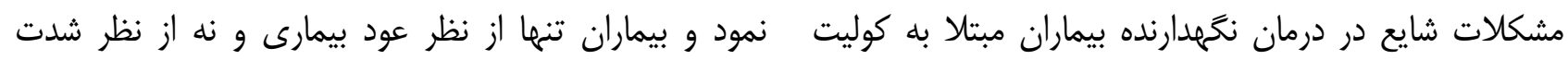

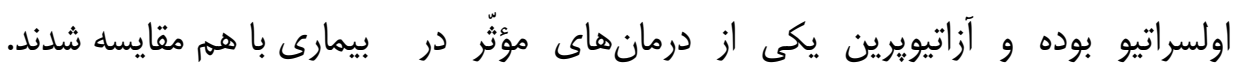

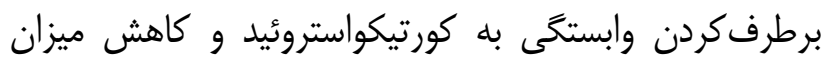

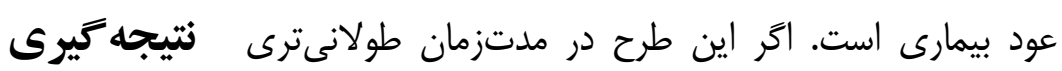

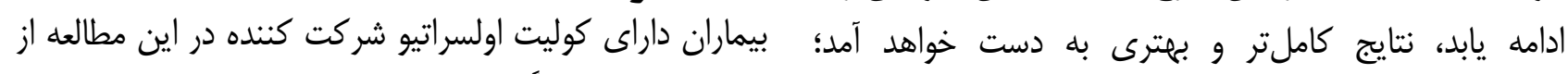

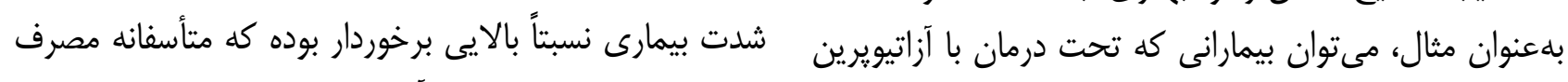

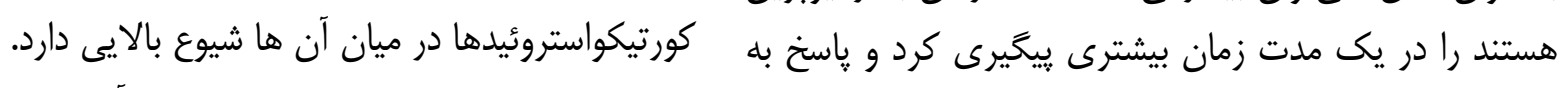

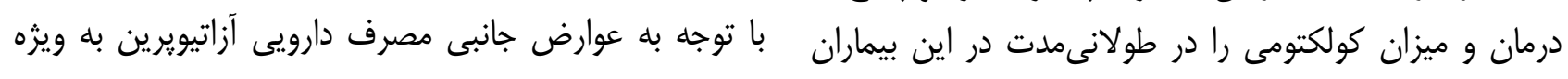

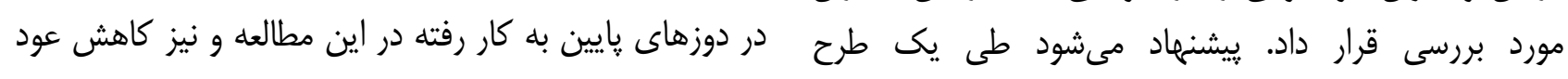

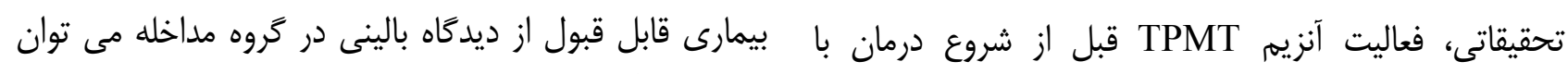

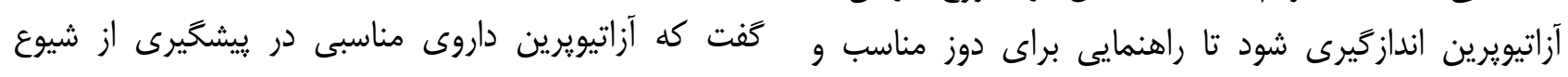

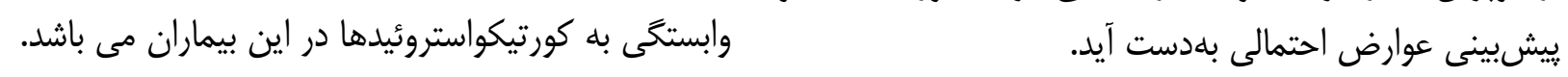

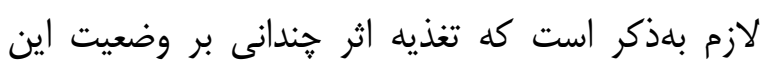

\section{تقدير و تشكر}

از معاونت تحقيقات و فناورى و دانشكده يزشكى دانشگاه

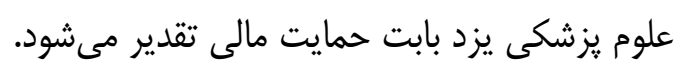

\section{تعارض منافع:}

نويسندكان اعلام مى دارند هيجَّونه تعارض منافعى در

اين مطالعه نداشتند.

بيمارى نداشته؛ در حالى كه عفونت (كه البته در اين مطالعه تحت كنترل بود) و بلويثه استرس بر شدت بـ بيمارى مؤثر

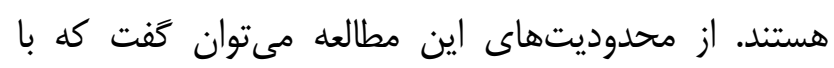

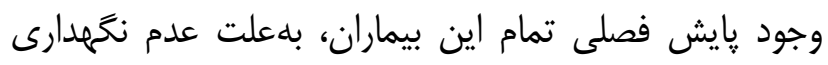

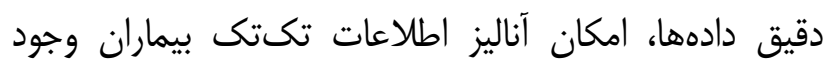

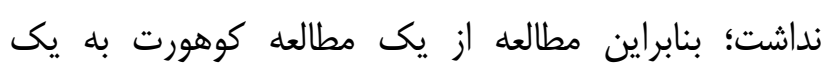

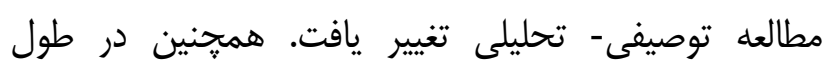

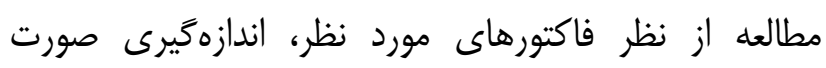

منابع:

1- D'haens G, Sandborn WJ, Feagan BG, Geboes K, Hanauer SB, Irvine EJ, et al. A review of activity indices and efficacy end points for clinical trials of medical therapy in adults with ulcerative colitis. Gastroenterology. 2007; 132(2): 763-86. DOI: 10.1053/j.gastro.2006.12.038

2- Bianchi Porro G, Cassinotti A, Ferrara E, Maconi G, Ardizzone S. Review article: The management of steroid dependency in ulcerative colitis. Aliment Pharm Ther. 2007; 26(6): 779-94. DOI: 10.1111/j.1365-2036.2007.03334.x

3- Wang Y, Ouyang Q; APDW 2004 Chinese IBD working group. Ulcerative colitis in China: Retrospective analysis of 3100 hospitalized patients. J Gastroenterol Hepatol. 2007; 22(9): 1450-5. DOI: 10.1111/j.1440-1746.2007.04873.X

4- Velayos F, Mahadevan U. Management of steroid-dependent ulcerative colitis: Immunomodulatory agents, biologics, or surgery? Clin Gastroenterol Hepatol. 2007; 5(6): 668-71.

5- Rodríguez-Moranta F, Soriano-Izquierdo A, Guardiola J. [Current status of treatment of inflammatory bowel disease]. Cir Esp. 2007; 82(5): 254-9. [Spanish] 
6- Ardizzone S, Maconi G, Russo A, Imbesi V, Colombo E, Bianchi Porro G. Randomised controlled trial of azathioprine and 5-aminosalicylic acid for treatment of steroid dependent ulcerative colitis. Gut. 2006; 55(1): $47-53$. DOI: $10.1136 /$ gut.2005.068809

7-McDonnell MJ, Dhar A. Azathioprine use in inflammatory bowel disease in South Durham - an insight into clinical practice. J R Coll Physicians Edinb. 2009; 39(2): 100-6.

8- Sood A, Midha V, Sood N, Avasthi G. Azathioprine versus sulfasalazine in maintenance of remission in severe ulcerative colitis. Indian J Gastroenterol. 2003; 22(3): 79-81.

9- Faubion WA Jr, Loftus EV Jr, Harmsen WS, Zinsmeister AR, Sandborn WJ. The natural history of corticosteroid therapy for inflammatory bowel disease: a population-based study. Gastroenterology. 2001; 121(2): 255-60.

10- Loftus EV Jr. Clinical epidemiology of inflammatory bowel disease: Incidence, prevalence, and environmental influences. Gastroenterology. 2004; 126(6): 1504-17.

11- Kappelman MD, Rifas-Shiman SL, Kleinman K, Ollendorf D, Bousvaros A, Grand RJ, et al. The prevalence and geographic distribution of Crohn's disease and ulcerative colitis in the United States. Clin Gastroenterol Hepatol. 2007; 5(12): 1424-9. DOI: 10.1016/j.cgh.2007.07.012

12- Dart RJ, Irving PM. Optimising use of thiopurines in inflammatory bowel disease. Expert Rev Clin Immunol. 2017; 13(9): 877-88. doi: 10.1080/1744666X.2017.1351298.

13- Connell WR, Kamm MA, Dickson M, Balkwill AM, Ritchie JK, Lennardjones JE. Long-term neoplasia risk after azathioprine treatment in inflammatory bowel-disease. Lancet. 1994; 343(8908): 1249-52.

14- Timmer A, Patton PH, Chande N, McDonald JW, MacDonald JK. Azathioprine and 6-mercaptopurine for maintenance of remission in ulcerative colitis. Cochrane Database Syst Rev. 2016; (5): CD000478. doi: 10.1002/14651858.CD000478.pub4.

15- Mantzaris GJ, Sfakianakis M, Archavlis E, Petraki K, Christidou A, Karagiannidis A, et al. A prospective randomized observer-blind 2-year trial of azathioprine monotherapy versus azathioprine and olsalazine for the maintenance of remission of steroid-dependent ulcerative colitis. Am J Gastroenterol. 2004; 99(6): 1122-8. DOI: 10.1111/j.1572-0241.2004.11481.x

16- Fraser AG, Orchard TR, Jewell DP. The efficacy of azathioprine for the treatment of inflammatory bowel disease: a 30 year review. Gut. 2002; 50(4): 485-9.

17- Kennedy NA, Kalla R, Warner B, Gambles CJ, Musy R, Reynolds S, et al. Thiopurine withdrawal during sustained clinical remission in inflammatory bowel disease: relapse and recapture rates, with predictive factors in 237 patients. Aliment Pharmacol Ther. 2014; 40(11-12): 1313-23. doi: 10.1111/apt.12980. Epub 2014 Oct 6.

18- Shi HY, Chan FK, Leung WK, Li MK, Leung CM, Sze SF, et al. Low-dose azathioprine is effective in maintaining remission in steroid-dependent ulcerative colitis: results from a territory-wide Chinese population-based IBD registry. Therap Adv Gastroenterol. 2016; 9(4): 449-56. doi: 10.1177/1756283X16643509 